\title{
ABULECENTRIC METHOD OF RENEWABLE, ALTERNATIVE AND SUSTAINABLE ENERGY A RADICAL WAY TOWARDS NATION'S DEVELOPMENT
}

\author{
Adefela Adekunle Nicholas \\ Centre for Renewable Energy Technology \\ Federal University of Technology \\ Akure, Ondo, Nigeria
}

\author{
Agbroko Oghenenyoreme Emakpo \\ Power Systems Control \\ Eko Electricity Distribution Company \\ Lagos, Nigeria
}

\begin{abstract}
Over the last decades of years, people have become more and more dependent on energy so much that they want, not just only energy but a sustainable one. An ever growing population requires an ever growing demand for energy. Nowadays, significance of energy cannot be denied, it is essential in every sphere of life. Energy sources can be broadly classified as renewable and non- renewable, with the knowledge that non-renewable sources of energy will eventually deplete, the importance of renewable sources cannot be overestimated. The most important aspect while utilizing them is their impact on the environment. This paper briefly presents the importance of renewable sources of energy, the use of alternative energy technologies towards achieving sustainable energy and step by step techniques and approach towards the radical way of achieving great national development through renewable, alternative and sustainable energy in an Abulecentric way. Renewable, Alternative and sustainable energy refers to energy sources whose rate of depletion is equal to the rate of replenishing, moving towards energy renewability and sustainability many factors are needed to be put into consideration such as the availability of the sources of energy, assessing the sources of energy, government policies concerning the sources, methods of harnessing renewable and sustainable energy sources, utilizing sustainable energy carriers, increasing efficiency, reducing environmental impact and improving socioeconomic activities towards achieving acceptable environment. Energy renewability and sustainability is of great importance to overall nation development particularly in economic development, standard of living, and environmental development so also philosophical, psychological, sociological and physical impacts.
\end{abstract}

Keywords: Renewable, Alternative, Sustainable, and Radical, Abulecentric.

\section{INTRODUCTION}

Over the last 2 century, earth occupants and inhabitants has become dependent and reliant on various renewable energy sources mostly from the sky, the ground and even the waste. For many years, during the ancient Greek till the $17^{\text {th }}$ century almost all energy used are from wind, water, firewood and muscular power.

Energy from the wind are used in powering our windmills, sailing the ship, cooking, while home heating are done using firewood more-so, muscular power and energy from both human and animal are used in the day to day activities. All the above mentioned sources of energy are all form of renewable, alternative and sustainable energy sources.

Energy is a necessity for the economic development of a country where every citizen has access to energy supply. Many functions necessary to present day living ground to halt when the supply of energy stops.

Renewable, Alternative and Sustainable energy gradually has become a worldwide necessity, resulting in optimal use of energy resources globally. The environmental impact of this energy processes has on daily bases increased as a result of its clean characteristics and environmental friendly ability which in turn leads to both local, regional and global demand for such energy. An increase in the demand of this energy results in perfect global demand of such energy in the world's economy as of today. This energy development is increasingly becoming a target to which many countries aspire.

Many ways have been adopted in defining renewable and sustainable energy but irrespective of any definition there are basically three (3) distinct component and content that must be put into consideration while defining the concept of such energy. These concept include the environment, social and the economics aspect of these three distinct component brings about the composition of renewable, alternative and sustainable energy.

Technical and Technological approach is seen as the major key in renewable and alternative energy while the social and economic are seen as the sustainable part of the renewable energy. The technology and technical aspect of renewable, alternative and sustainable energy in this paper is taken from the field experience of the authors as a renewable energy project officer and as a professional technologist and instructor in the field of renewable energy and also the electricity distribution.

This approach is also taken to be pragmatic, which is often at the Centre of engineering activities, and because it focuses on the technical necessities to achieve such form of energy, the immediate ideas may not be the best approach that will be taken 


\section{International Journal of Engineering Applied Sciences and Technology, 2020 \\ Vol. 5, Issue 7, ISSN No. 2455-2143, Pages 41-45 \\ Published Online November 2020 in IJEAST (http://www.ijeast.com)}

by renewable energy business men and women, economists, industry leaders, universities, politicians or sociologists because their view and taught on renewable and sustainable energy differs.

The realistic approach adopted is considered necessary and perfect by the authors in addressing the fundamental issues and challenges related to renewable, alternative and sustainable energy. Economics and politics of energy policy making varies temporally, spatially and geopolitically in all ramification thereby underlying fundamental issues involved in achieving such energy system technically.

Secondly, prices of energy are not in any way stable as they varies directly proportional to political instability, potentials like adverts, taxes, commissions and incentives and government policies.

\section{BACKGROUND}

In appreciating the concept of renewable, alternative and sustainable energy it is necessary to define the basic and the rudiment of what we referred to as energy and its concept.

\section{A. Energy}

Energy is the basic necessity for the economic development of a country where every citizen has access to energy supply. Law of conservation of energy states that energy can neither be created nor destroy but can be converted from one form to another and in view of this conservation law, energy has been defined in various ways depending in the area of utilization. Energy can be defined as the rate or ability to do work, it can also be defined as power with respect to time.

\section{B. Forms of Energy}

Energy exists in various forms and sources namely renewable energy and non-renewable energy.

Energy forms: Energy comes in a variety of forms, including fossil fuels, fossil fuel-based products (e.g., gasoline, diesel fuel and paraffin oil), uranium, electricity (heat or hydro, nuclear work (including mechanical energy in a moving engine shaft), heat, heated substances (e.g., steam, hot air), light and other electromagnetic radiation.

\section{Source of Renewable and Sustainable Energy}
1) Solar
2) Wind
3) Biomass
4) Bio-fuel
5) Tidal
6) Hydro
7) Geo-thermal

All these sources are basically available in abundance in our country called Nigeria but the utilization of these abundance resources is extremely low.
Fig 1. Chain diagram of renewable energy sources:

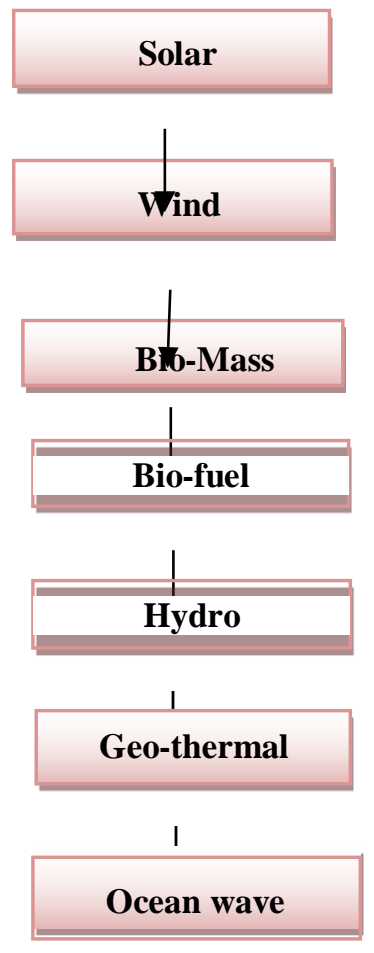

1) Solar system- solar system comprises of the sun and the planets revolving around it in an elliptical orbit. Solar energy refers to the insolation from the sun as a result of the abundant energy called photons released by the sun. The sun is about 149.6 million $\mathrm{km}$ above the ground level with radiance energy of approximately 100 times the mass of the earth, the sun releases energy called photons and these photons are released in packets or in bundles, these photons released by the sun when incident on a semiconductor either silicon or germanium set the electron in motion thereby reducing the depletion layer of the semiconductor and the semiconductor starts conducting. These semiconductors are today referred to as solar module. Photons from the sun can also be used to produce light and heat. Heating, using the energy from the sun can either be in a passive or in an active way. In passive heating, structures are erect with heat absorbing surface and window to maximize solar heating of the home. While in active solar system of heating energy are collected by a collector and then transferred down to where it will be used.

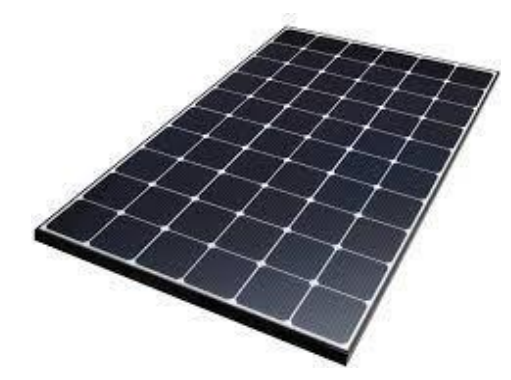




\section{International Journal of Engineering Applied Sciences and Technology, 2020 \\ Vol. 5, Issue 7, ISSN No. 2455-2143, Pages 41-45 \\ Published Online November 2020 in IJEAST (http://www.ijeast.com)}

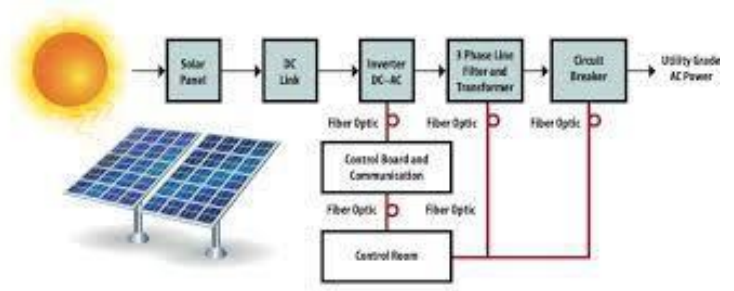

Source: https://www.pinterest.com/pin/61023781822818 $6153 / ?$ auto $\operatorname{login}=$ true

2) Wind- Wind energy is a form of renewable energy in which energy from the wind is converted into electrical energy that is useful for human. This energy depends on the energy of the sun and it is a very clean source of energy. Wind turbine converts the kinetic energy from the wind into mechanical energy which later in turn is converted to electrical energy.

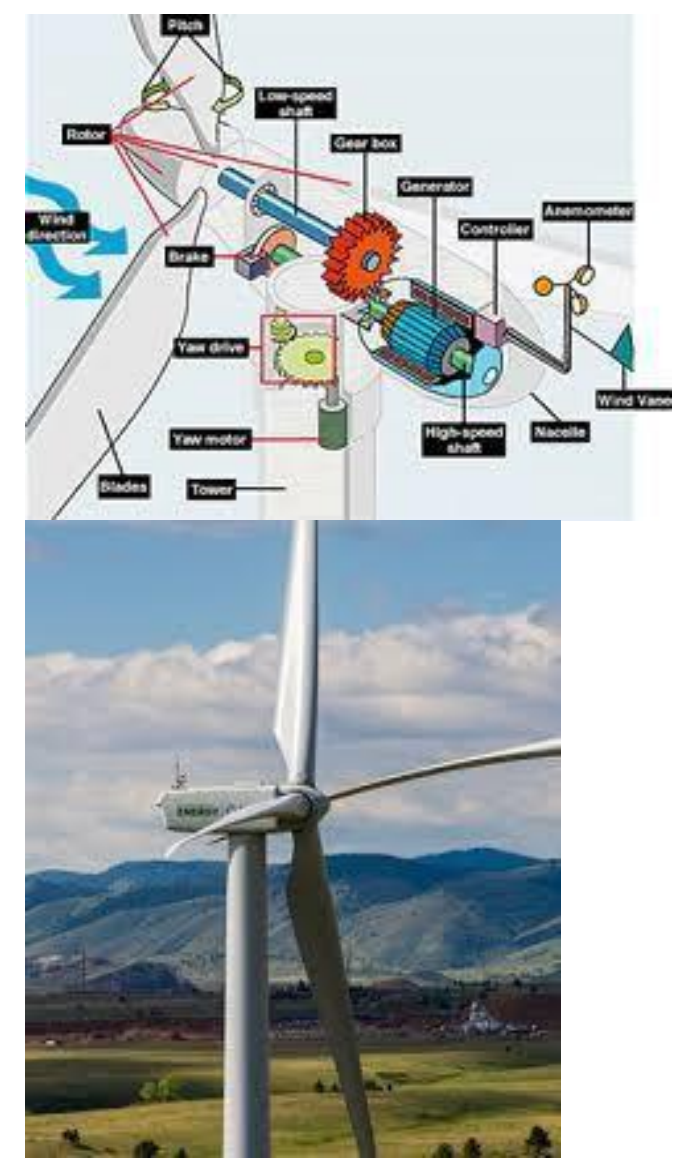

Source: National Renewable Energy Laboratory, U.S. Department of Energy (public domain

3) Bio-mass- A form of renewable energy source formed from decomposition of organic materials. Such materials include plants and animals. Biomass contains energy absorbed from the sun through plant photosynthesis, and when the plant is burnt or decomposed it releases the energy in form of heat. This heat is then used in the production of electricity.

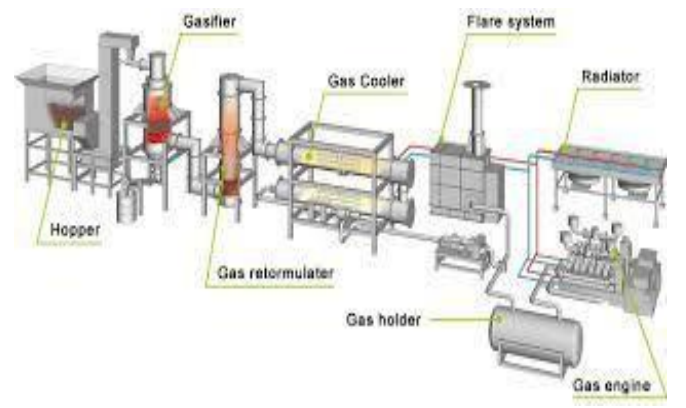

Source: https tem/img/bg_plant_power.jpg

4) Bio-fuel- These are renewable energy fuel produced from series of biological process such as animal dung in an anaerobic environment and also wastes in an anaerobic environment.

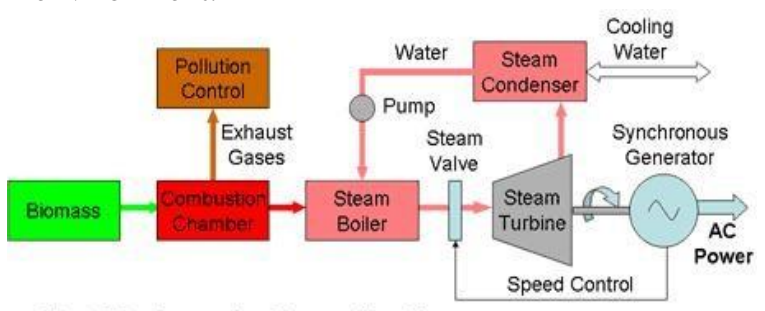

Electricity Generation Powered by Biomass

Source: https://www.mpoweruk.com/biofuels.htm

5) Hydro- The second most available and abundant renewable energy source is the hydro system. As implied, the potential energy stored in the dammed water is converted to kinetic energy to drive a turbine connected to a generator to produce electricity.

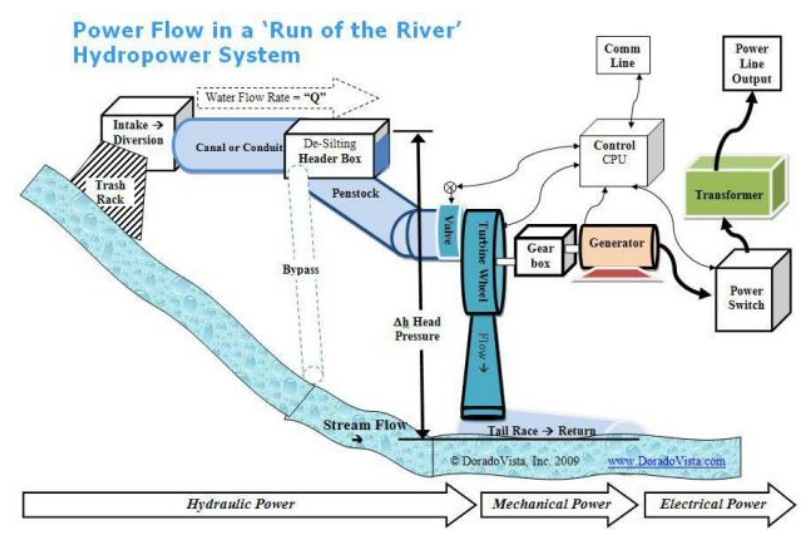

Source:https://i.pinimg.com/originals/52/c0/2d/52c02d46 2f569993b880504eaa268a57.jpg

There are four basic types of hydro-power system

1) Run-Off river hydro power

2) Storage hydro power

3) Pumped storage hydro power

4) Off shore hydro power

1) Run-Off River Hydro Power- a flowing river is made to flow into a turbine through the pen-stock, this type of system has little or no storage but provides a continuous supply of electricity for operation on daily demand through water flow. 


\section{International Journal of Engineering Applied Sciences and Technology, 2020 \\ Vol. 5, Issue 7, ISSN No. 2455-2143, Pages 41-45 \\ Published Online November 2020 in IJEAST (http://www.ijeast.com)}

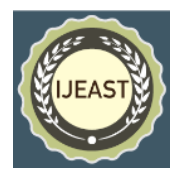

This type of hydro system can be sub-divided into two called mini and micro hydro-power system. The Mini hydro refers to a hydro system less than $1000 \mathrm{~kW}$ while the Micro hydro power refers to a hydro system less than $200 \mathrm{Kw}$. Basically such type of system are used in powering small communities, single family apartment and small enterprise.

2) Storage Hydro Power- Power system with large reservoir of water acquired through dam. Electricity is produced by converting the potential energy stored in the water to kinetic energy to drive a turbine which in turn drives a generator to produce electricity. The dam of such hydro system can be concrete gravity dam, rock filled dam, gabion dam, concrete reinforced gabion dam and earth dam.

3) Pump Storage Hydro Power-This type of system has an upper reservoir through which water is discharged into the turbine and also a lower reservoir that collect the water from the tail race. A pump is located at the output of the lower reservoir to pump back the water at the lower reservoir back into the upper reservoir and such system can be considered as a close loop hydro power.

4) Offshore Hydro power-This type of system uses the tidal current or the ocean wave to generate electricity.

5) Geo-thermal-These are energy generated and stored in the interior of the earth crust. This energy originated right from the creation of the earth and also from the spontaneous disintegration of radioactive material. It is noted that $12 \mathrm{ft}$ to $40 \mathrm{ft}$ below the earth surface has a constant temperature throughout the year irrespective of the location. The heat in form of energy is converted into electricity by driving a turbine and also used for cooling and warming through heat exchanger called heat pump.

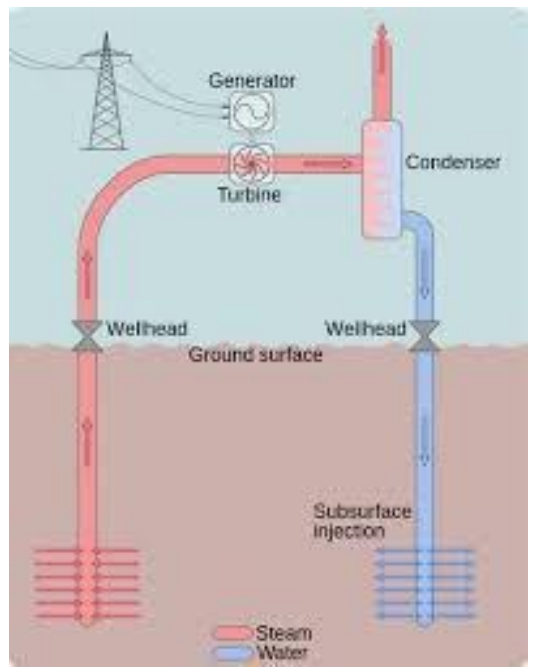

Source: https://energyeducation.ca/encyclopedia

/Geothermal_power_plants

6) Ocean wave- These are waves produced by the movement of the ocean. The wave is converted to energy through turbines. This energy is produce when electricity generators and turbines are placed on or under the ocean. The energy provided is most often used in desalination plants, power plants and water pumps. Energy output is determined by wave height, wave speed, wavelength, and water density. All these energy sources that are renewable, alternative and sustainable are present in every area in our country which in turn can produced adequate employment for our citizen in Nigeria.

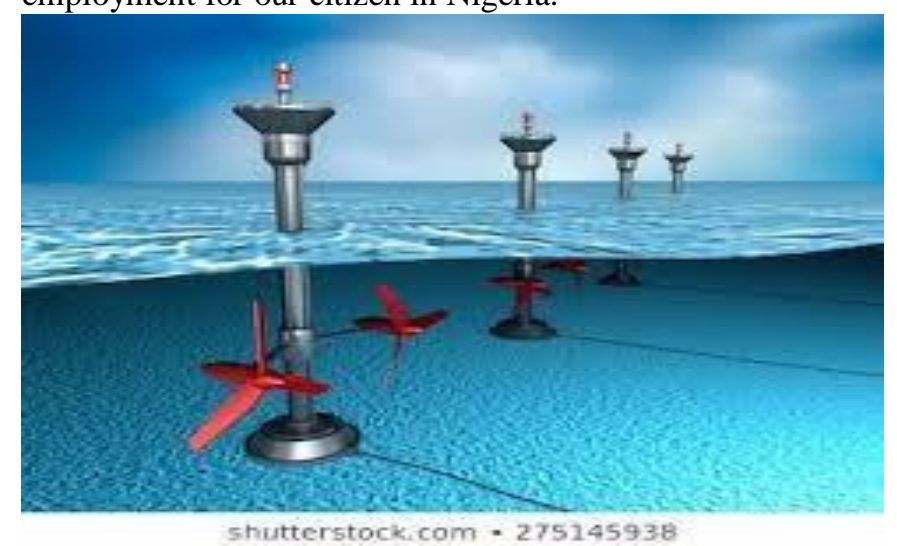

Source:https://www.shutterstock.com/search/wave +ene rgy

\section{What Is Renewable Energy?}

Depending on the area of view, scholars define renewable energy in different form. Some define renewable energy as a clean energy coming from natural sources or processes that are constantly replenished while some researchers refers to it as a green energy or clean energy. Adefela 2018 defines renewable energy as the energy whose rate of depletion is equal to the rate of replenishing. In Nigeria today harnessing every sources of renewable energy will drastically develop the nation both economically and in human capacity such as Transportation, Communication Network System, Electricity etc.

\section{III.}

\section{METHODOLOGY}

A. How Does Abulecentric Renewable, Alternative And Sustainable Energy Develop A Nation?

The Abulecentric renewable, alternative and sustainable energy system refers to a small modular unit of renewable energy system. The word "Abule" refers to a small settlement, village or small community in Yoruba language in Nigeria. The impact of various energy sources both renewable and non-renewable cannot be over emphasized because individual sources have one or two impact on the environment and the nation. As we all know that fossil fuels has done more harm to our environment than good and such harms include the depletion of the ozone layer, increase in the rate of cancer, air pollution, water pollution, damage to public health, loss of wild life and global warming. However in terms of Abulecentric energy system with sources from solar, wind, bio fuel, geothermal, hydro etc., a positive impact is assured on national development. Technology used in harnessing the energy from the source will determine the level of impact and development these will bring to the nation. Renewable energy can bring a drastic and rapid growth to the society especially at the local level by focusing on small community and developing them a village at a time. Renewable energy can be a solid path to true local, state and central government. There are various way which renewable energy can help in the rapid growth of a society in a small scale called 


\section{International Journal of Engineering Applied Sciences and Technology, 2020 \\ Vol. 5, Issue 7, ISSN No. 2455-2143, Pages 41-45 \\ Published Online November 2020 in IJEAST (http://www.ijeast.com)}

Abulecentric and such ways include.

1) Modular operating system unit in which society will be develop bit by bit.

2) Governance decentralization such that each sphere will be autonomous in his operations.

3) Renewable energy will reduce rural to urban migration.

4) Improve local gain and national advancement

5) Equality in the consumption of natural resources.

6) Erasing or Reducing unemployment to the barest minimal.

7) Reducing carbon emission thereby reducing sickness associated with the emission.

8) Diversity in strength of individual ethnics and region

9) Enhancing the development of local areas because the citizen will be closer to the system to monitor and supervise it and the more they are closer to the system the more they enjoy the dividend.

10) Improve security network from the local level to the central government.

11) Encourage and promote local investors.

12) Solves national power problem.

13) Cost effective and efficient energy supply at the local level down to the central level.

14) Employment and capacity building.

15) Rapid industrialization and lot more.

\section{CONCLUSION}

Nigeria with a population of over two hundred million $(200,000,000)$ people, the electricity generation is not up to 6000MW which is grossly inadequate for daily use and hence no meaningful development can be achieved with such generation. Shortage of energy supply for basic daily use has resulted in massive load shedding in which certain areas have been restricted to predetermined hours of energy supply.

Implementing an Abulecentric sustainable, alternative and renewable form of energy will make energy available to certain clusters of towns and villages and hence reduce the demand for energy on Nigeria national grid, reduce load shedding and hence make room for national development in-term of energy availability and revenue generation.

Since the natural renewable energy sources are abundantly present, it is necessary that nation's explore the availability of this resource right from local level such that each system is done in a local way and are autonomous in their area of location. With the above mentioned it is certain that if Nigeria as a country could explore the renewable energy sources in an Abulecentric manner there is going to be a great development in-terms of revenue generation, human capacity building, adequate energy supply etc.

\section{ACKNOWLEDGEMENT}

The author and the co-author sincerely acknowledge the support of the former director prof.Olu-Lafe and all other administrator of the Centre and the school at large. The author and the coauthor also appreciate the reviewers for their precious time taking to review the paper.

\section{REFERENCE}

1.Blankenship.S.2004.Study finds electricity beats hydrogen for power storage and delivery. Power Engineering, 108(8), (pp. 1416).

2.Blok k. (2005).Enhanced policies for the improvement of electricity efficiencies energy policy 2005:33(13):1635-41

3.EIA. (2012).international Energy statistics: Electricity Capacity for Kenya, Morocco, South Africa and the United States Washington DC US Department of Energy.

4.ERC. (Energy Regulations Commission). 2011. Scaling up Renewable Energy Plan.2011.Nairobi, Kenya: (pg.1-14).

5.Fadaeenejad,M.;Saberian,A.M.;Facade,M.;Radzi,M.A.; Hizam,H.;Abkadir,M.Z.(2013).The Present and Future of Smart Power Grid in Developing Countries. Renewable and Sustainable Energy Reviews 29, (pg828- 834).

6.Fouquet, R. (2008).Heat, Power and Light: Revolutions in Energy Service.

7.Gilles Carbonnier and Jacques Grind Vald. (2008).Energy and Development https://doi.org/10.400/Poldev.724.

8.GIZ. (2005).Rural Hydro Power Civil Engineering

9.International Energy Agency (IEA). (2016).World Energy Outlook.Paris.France.

10.International Energy Agency (IEA). (2010).World Energy Outlook 2010(Paris: IEA) Doi: 10.17 87/20725302

11.Karunya Rajha.G.S; Shilaja.C. (2019). Optimization Strategy for Sustainable Development of Renewable Energy System 2019: Vol 9 Issue-282

12.National Renewable Energy Laboratory (NREL). (2002).An Economic Valuation of Geothermal Production Tax Credit.

13.National Wind Coordinating Committee (NWCC). (2001).Distributed Wind Power Assessment.

14.Olu-Lafe (2017). Abulecentric: Rapid Development of Society Catalyzed at Local Community Level.

15.World Energy Council (WEC). (1993).Energy for Tomorrow's World, the Realities, The Real Options and Agents for Achievement.

16.World Summit on Sustainable Development (2002).Declaration. WSSD Johannesburg. 